\title{
Numerical modeling on drilling fluid and cutter design effect on drilling bit cutter thermal wear and breakdown
}

\author{
Ahmad Zhafran Ayop ${ }^{1} \cdot$ Ahmad Zafri Bahruddin ${ }^{1}$ - Belladonna Maulianda ${ }^{1}$ Aruvin Prakasan ${ }^{1}$. \\ Shamammet Dovletov ${ }^{1} \cdot$ Eziz Atdayev $^{1} \cdot$ Ahmad Majdi Abdul Rani $^{1} \cdot$ Khaled Abdalla Elraies $^{1} \cdot$ Tarek Al-arbi Ganat $^{1}$. \\ Reza Barati ${ }^{2}$. Sia Chee Wee ${ }^{1}$
}

Received: 6 February 2019 / Accepted: 1 October 2019 / Published online: 11 October 2019

(c) The Author(s) 2019

\begin{abstract}
The unconventional reservoir geological complexity will reduce the drilling bit performance. The drill bit poor performance was the reduction in rate of penetration (ROP) due to bit balling and worn cutter and downhole vibrations that led to polycrystalline diamond compact (PDC) cutter to break prematurely. These poor performances were caused by drilling the transitional formations (interbedded formations) that could create huge imbalance of forces, causing downhole vibration which led to PDC cutter breakage and thermal wear. These consequently caused worn cutter which lowered the ROP. This low performance required necessary improvements in drill bit cutter design. This research investigates thermal-mechanical wear of three specific PDC cutters: standard chamfered, ax, and stinger on the application of heat flux and cooling effect by different drilling fluids by using FEM. Based on simulation results, the best combination to be used was chamfered cutter geometry with OBM or stinger cutter geometry with SBM. Modeling studies require experimental validation of the results.
\end{abstract}

Keywords PDC cutter design · Thermal-mechanical wear · FEM modeling · Drilling fluid cooling effect

\section{Introduction}

Oil and gas industries gradually shifted their focus in subsurface over the last few decades. Historically, the main concern of petroleum industry was on conventional oil and gas as they are easily accessible. As conventional oil and gas plays were exhausted and drilling activities declined, unconventional resources were getting more attention. Horizontal well drilling introduced technical and economic feasibility into the unconventional reserve exploration. Drilling at greater depth during horizontal well drilling requires optimization to ensure the highest efficiency and economic value of drilling operations. The key to achieve optimum project economics and reduce field development costs is maintaining high ROP in the lateral interval.

Aruvin Prakasan

aruvinprakash@gmail.com

1 Department of Petroleum Engineering, University Technology PETRONAS, 32610 Seri Iskandar, Perak Darul Ridzuan, Malaysia

2 University of Kansas, 1450 Jayhawk Blvd, Lawrence, KS 66045, USA
Massive developments on PDC technologies were constantly introduced to overcome hole cleaning and penetration rate challenges. Therefore, the invention of the PDC bit in the mid-1970s has made substantial changes in the materials, processes, and geometry of the PDC cutter. These improvements ranged from innovation in management of the diamond particle size and density, diamond table thickness, nonplanar interfaces for stress management, chamfers, surface finish, thermal stability, and high-pressure sintering. However, drilling with PDC bits in very hard, abrasive, and complex formations posed huge challenges. As in the case with interbedded formation, when drilling progresses from soft formation into harder formation, the cutter may be overloaded at high weight on bit (WOB) or ROP may get reduced at lower WOB. The huge imbalance of forces due to transitional formations causes downhole vibrations. This vibrations may result in the premature breaking of PDC cutter, bit balling and worn cutter, all of which leads to lowered ROP. The key to reduce field development costs and improve project economics is by increasing ROP with extended footage.

The previous studies on PDC drill bit crown and PDC drill bit cutter had proposed several design optimizations 
based on laboratory experiments (Curry et al. 2015; Oliveira et al. 2015; Stockey et al. 2014; Azar et al. 2013; Yahiaoui et al. 2013) and finite element modeling (FEM) (Oliveira et al. 2015; Rani et al. 2015; Stockey et al. 2014; Al-Muhailan et al. 2013; Ju et al. 2014; Freeman et al. 2012). Oliveira et al. (2015) proposed a new drill bit cutter design called dual-chamfer cutters for drilling in interbedded formations. Laboratory testing was done on the dual-chamfer cutters using vertical turret lathe (VTL) and visual pressurized single-point-cutter (VSPC) test machine and a monotonic loading test. The laboratory test results showed increment in average meter drilled by $40 \%$ while keeping a comparable constant ROP. Oliveira et al. (2015) also modeled the dual-chamfer cutters using FEM, and the obtained results showed the face loading test on the individual cutters; the cutter experienced a total load vector during rock cutting that could be broken into three forces along the Cartesian axis (normal, tangential, and radial forces). The tangential three forces were responsible for surface failures due to the diamond table failed in tension. The FEM results showed a significant drop in tensile stresses in dual-chamfer cutter. A monotonic face loading laboratory test was done to verify the FEM results. Oliveira et al. (2015) had not modeled the cutter breakdown in different forces such as normal forces and radial forces.

In this study, modeling of drill bit cutter breakdown in different forces such as normal forces and radial forces has been performed using explicit FEM, which is known as a lacking area of the previously mentioned modeling studies. Curry et al. (2015) performed experimental work in salt formation to investigate different drill bit cutter density effects on drill bit durability, hole-bottom coverage, MSE, and mechanical efficiency using visual single-point-cutter test machine. Their work limitations were the nonexistence of experiments on the effect of different drilling fluid types on cutter thermal wear. Stockey et al. (2014) had modeled the FEM-CFD to analyze the thermal wear on planar and nonplanar cutters. Stockey et al. (2014) applied a uniform heat flux to both cutters, but they did not perform any modeling on the drilling fluid cooling effect on the drill bit cutter to reduce the thermal wear. Others (Oliveira et al. 2015; Rani et al. 2015; Al-Muhailan et al. 2013; Ju et al. 2014) also did not consider the drilling fluid cooling effect on drill bit cutter. Freeman et al. (2012) performed experiments on the thermal mortality of the PDC planar cutter with two different drilling fluids which were water- and xanthan-based freshwater drilling fluid. Their work limitation was that they did not investigate the thermal wear on dual-chamfer cutter. This study will investigate the thermal wear on single chamfer, ax, and stinger cutters. The mentioned previous studies were lacking in the modeling of the drilling fluid cooling effect on drill bit cutter, on the top of cutter breakdown in different forces, and the effect of three various drilling fluids (synthetic-based mud, oil-based mud, and water-based mud) on different shaped cutters (standard chamfered, ax, and stinger) by using explicit FEM.

Some of the modeling techniques used by the previous authors involve introducing stationary cutter and dynamic cylindrical formation rotating around its center (Bilgesu et al. 2008) and stationary formation and moving cutter. Besides the common continuum element method, some authors have also used smoothed particle hydrodynamics (SPH) method to simulate the cutter scrapping the formation (Pei et al. 2013). SPH method was used to reduce the nonconvergence issue which is faced in simulating the model with geometry nonlinearities. Another method to tackle nonconvergence issues in Abaqus standard (implicit solver) was the implementation of explicit solver, which was used in this study.

\section{Governing equations}

Within this section, all fundamental equations involved in the modeling such as conservation of mass, conservation of linear momentum, convection-diffusion equation, conversion of energy, stress tensor, and heat flux vector equation are demonstrated with required explanation prior to methodology.

\section{Conservation of mass}

The conservation of mass is given as

$\frac{\partial \rho_{m}}{\partial t}+\operatorname{div}\left(\rho_{m} v\right)=0$

where $\frac{\partial}{\partial t}$ is partial derivative with respect to time, $v$ is the velocity vector, and $\rho_{m}$ is known as the density of suspension and given as

$\rho_{m}=\left(1-\phi \rho_{\mathrm{f} 0}\right)+\phi \rho_{\mathrm{s} 0}=a \phi \rho_{\mathrm{f} 0}+\phi \rho_{\mathrm{s} 0}$,

where $\rho_{\mathrm{f} 0}$ represents pure density of fluid, $\rho_{\mathrm{s} 0}$ is given as the density of solid components in the reference configuration, and $\phi$ represents volume fraction of the particles.

\section{Conservation of linear momentum}

The conservation of linear momentum is given as

$\rho_{m} \frac{\mathrm{d} v}{\mathrm{~d} t}=\operatorname{div} \boldsymbol{T}+\rho_{m} \boldsymbol{b}$,

where $\rho_{m}$ is the density of suspension, $\boldsymbol{b}$ is given as the body force vector, and $\boldsymbol{T}$ is the Cauchy stress tensor and the total material time derivative, which is $\frac{\mathrm{d}(\cdot)}{\mathrm{d} t}$ and is derived as $\frac{\mathrm{d}(\cdot)}{\mathrm{d} t}=\frac{\mathrm{d}(\cdot)}{\mathrm{d} t}+[\operatorname{grad}(\cdot)] \boldsymbol{v}=a \phi \rho_{\mathrm{f} 0}+\phi \rho_{\mathrm{s} 0}$. 


\section{Convection-diffusion equation}

Convection-diffusion equation is

$\frac{\partial \phi}{\partial t}+v \frac{\partial \phi}{\partial x}=-\operatorname{div} N$

where the term at the left side represents the accumulation rate of particles with convected particle flux and the term at the right side represents the diffusive particle flux. Brownian motion is given as $N$, the variation in interaction frequency and viscosity.

\section{Conversion of energy}

Conversion of energy is given as

$p_{m} c_{m} \frac{\mathrm{d} \theta}{\mathrm{d} t}=\boldsymbol{T}: \boldsymbol{L}-\operatorname{div} \boldsymbol{q}+p_{m} r$,

where $\boldsymbol{L}$ is the gradient velocity, $q$ is the heat flux vector, and $r$ is the specific radiant energy. $p_{m} c_{m}$ is the heat capacity of suspension and derived as

$p_{m} c_{m}=(1-\phi) \rho_{\mathrm{f} 0} c_{\mathrm{pf} 0}+\phi \rho_{\mathrm{s} 0} c_{\mathrm{ps} 0}$

where $c_{\mathrm{pf} 0}$ and $c_{\mathrm{ps} 0}$ are the specific heat capacity of fluid and solid particles, consecutively.

\section{Stress tensor}

Generally, the stress tensor equation is given by the nonlinear model and it may include yield stress and viscous stress, and the equation is given as

$T=T_{\mathrm{Y}}+T_{\mathrm{V}}=-p I+\mu_{m} D$,

where yield stress and viscous stress are $T_{\mathrm{Y}}$ and $T_{\mathrm{V}}$, respectively.

\section{Heat flux vector}

Heat flux equation is

$\boldsymbol{q}=-k \nabla \boldsymbol{\theta}$,

where $k$ is the thermal conductivity of the material and it may depend on various properties such as concentration, temperature, and shear rate, and it may be replaced with $k_{m}$ or $k_{\text {eff }}$ depending on the modeling input parameter.
Table 1 Dimensions of the specified cutters

\begin{tabular}{lllll}
\hline Type/property & $\begin{array}{l}\text { Tungsten- } \\
\text { carbide height } \\
(\mathrm{mm})\end{array}$ & $\begin{array}{l}\text { PDC height/ } \\
\text { peak height } \\
(\mathrm{mm})\end{array}$ & $\begin{array}{l}\text { Diam- } \\
\text { eter } \\
(\mathrm{mm})\end{array}$ & $\begin{array}{l}\text { Chamfer/ } \\
\text { peak radius } \\
(\mathrm{mm})\end{array}$ \\
\hline $\begin{array}{l}\text { Standard } \\
\text { chamfered }\end{array}$ & 8 & 2 & 13 & 0.2 \\
Ax & 8 & 3 & 13 & 3 \\
Stinger & 8 & 4 & 13 & 0.5 \\
\hline
\end{tabular}

Table 2 Properties of the formation

\begin{tabular}{ll}
\hline Property & Sand \\
\hline Young's modulus & $16.65 \mathrm{GPa}$ \\
Poisson's ratio & 0.1893 \\
Conductivity & $3.35 \mathrm{~W} / \mathrm{m}^{\circ} \mathrm{C}$ \\
Density & $2000 \mathrm{~kg} / \mathrm{m}^{3}$ \\
Specific heat & $920 \mathrm{~J} / \mathrm{kg}{ }^{\circ} \mathrm{C}$ \\
Cohesion yield stress & $27.2 \mathrm{MPa}$ \\
Absolute plastic strain & 0 \\
Friction angle & $27.8^{\circ}$ \\
Dilation angle & $12^{\circ}$ \\
\hline
\end{tabular}

\section{Methodology}

In this study, the software used to create the model and to run the simulation was ABAQUS FEA by Simulia.

\section{Part}

Within the part menu, the geometrical features of the model were introduced. Two components that were introduced in each model are cutter and formation. The cutter dimensions were retained as they are in real life without scaling. Dimensions for the cutters are summarized in Table 1.

Formation was introduced as a cuboid element with dimensions of $5 \mathrm{~mm} \times 5 \mathrm{~mm} \times 100 \mathrm{~mm}$. The dimension was chosen to be $5 \mathrm{~mm} \times 5 \mathrm{~mm} \times 100 \mathrm{~mm}$ to reduce the number of elements generated and reduce the running time for the simulation.

\section{Property}

To study thermo-mechanical wear of the cutters, the thermal and mechanical properties of the formation and cutters were introduced in the model. Tables 2 and 3 summarize the properties introduced in the model for formation, PDC and tungsten-carbide, respectively.

The cooling effect of the drilling fluid was introduced using the surface film interaction criterion. This ensures 
Table 3 Properties of the PDC and tungsten-carbide

\begin{tabular}{lll}
\hline Property/material & Tungsten-carbide & PDC \\
\hline Conductivity $\left(\mathrm{W} / \mathrm{m}^{\circ} \mathrm{C}\right) @ 20{ }^{\circ} \mathrm{C}$ & 200 & 900 \\
Conductivity $\left(\mathrm{W} / \mathrm{m}{ }^{\circ} \mathrm{C}\right) @ 200{ }^{\circ} \mathrm{C}$ & 50 & 20 \\
Density $\left(\mathrm{kg} / \mathrm{m}^{3}\right)$ & 1550 & 3510 \\
Young's modulus $(\mathrm{GPa})$ & 685 & 925 \\
Poisson's ratio & 0.2 & 0.086 \\
Expansion coefficient $\left({ }^{\circ} \mathrm{C}^{-1}\right)$ & $4.6 \times 10^{-6}$ & $3.8 \times 10^{-6}$ \\
Specific heat $\left(\mathrm{J} / \mathrm{kg}{ }^{\circ} \mathrm{C}\right)$ & 230 & 790 \\
\hline
\end{tabular}

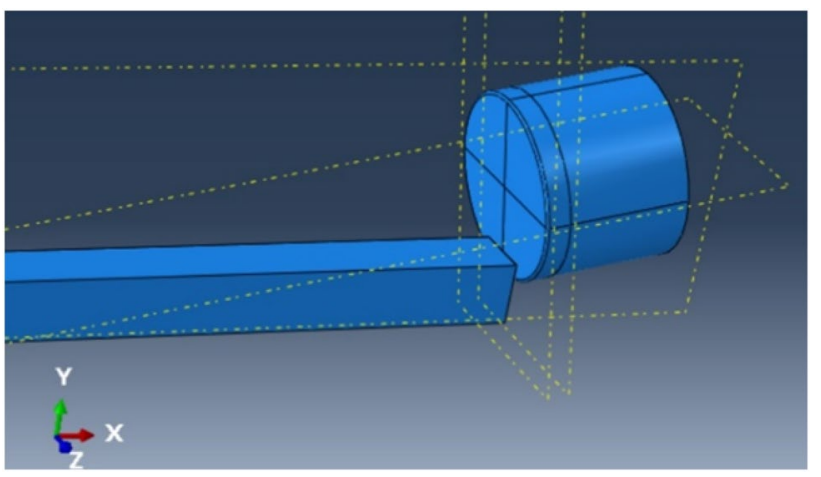

Fig. $13 \mathrm{D}$ view of interaction of formation and cut

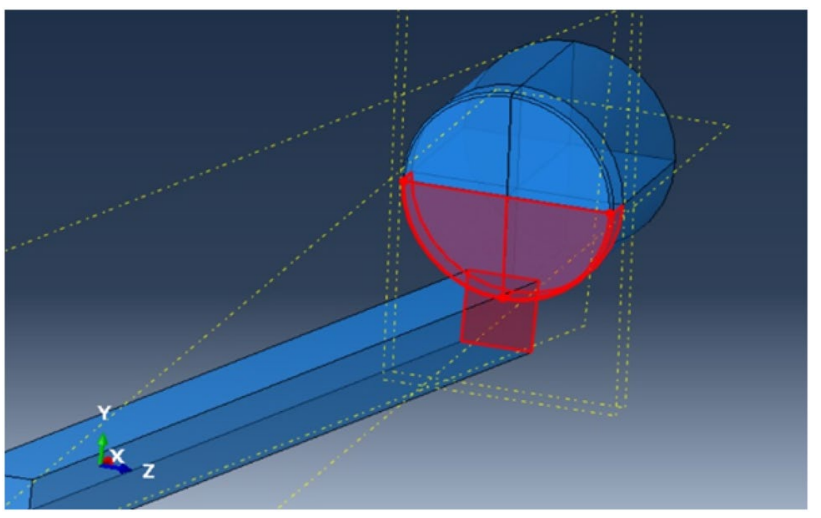

Fig. 2 Interacting surfaces of formation and cutter

the introduction of cooling effect while incorporating lesser fluid properties. The necessity of reducing the number of components to be simulated arises due to the necessity to reduce simulation time.

\section{Assembly}

In the assembly menu, the parts were placed in $3 \mathrm{D}$ space as shown in Fig. 1. And within this menu, the interaction

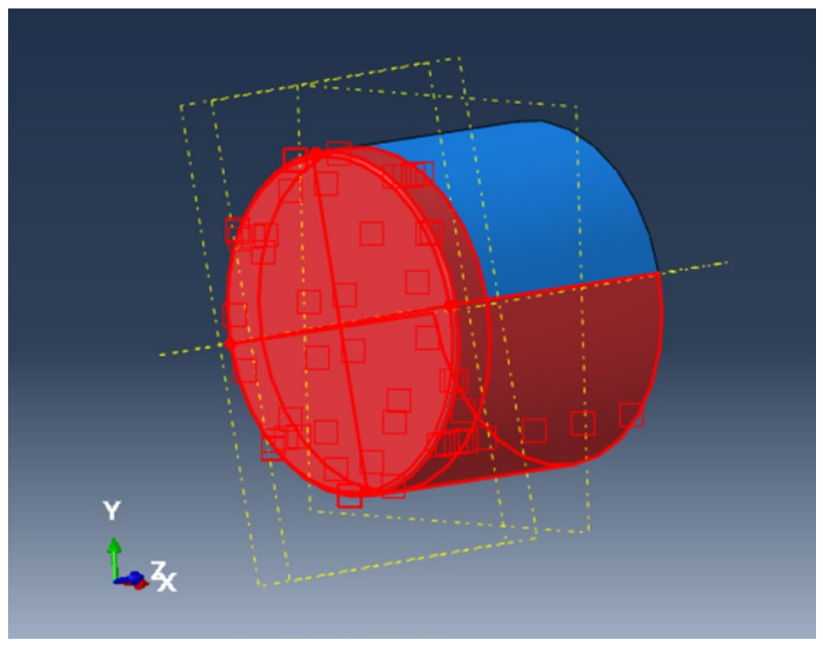

Fig. 3 Interaction surface of the conventional cutter

surfaces were introduced to ensure that internal elements of formation interact with the cutter, Fig. 2.

\section{Step}

Within the step menu, new dynamic explicit coupled temperature-displacement step was introduced. Through this step, it was possible to simulate thermo-mechanical wear. In the step menu, the nonlinear geometry option was turned on.

\section{Interaction}

Within the interaction menu, general interaction property was introduced to account for friction and frictional heat generation. The friction factor used was 0.125 (Yari et al. 2018). The friction factor generated heat which was emitted to the formation and the cutter in same amount.

Another interaction introduced was the cooling effect of drilling fluid. Temperature-dependent surface film coefficient based on the literature was introduced with the sink temperature amplitude to introduce a linear temperature gradient which is observed during drilling. Cooling effect was introduced to the points of major contact of drill bit cutter. The interaction surface for the conventional cutter is demonstrated in Fig. 3.

\section{Load}

In this menu, present loads, boundary conditions, and predefined fields were introduced. No any load was applied to reduce the number of uncertainties in the analysis. "ENCASTRE" boundary condition was introduced to the bottom of the formation to restrict any directional or rotational movement of the formation (Fig. 4). At the initial step, 


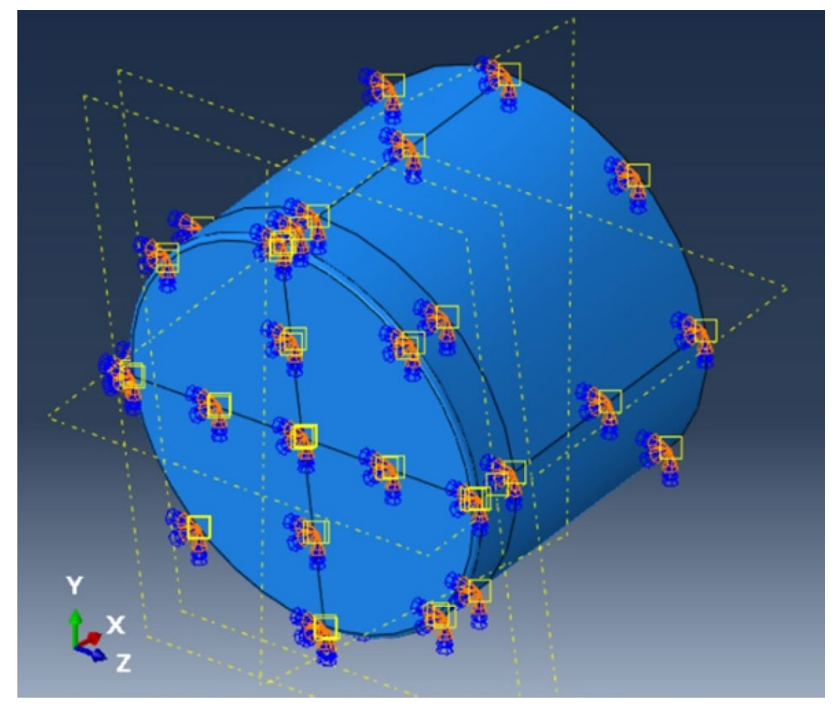

Fig. 4 Boundary conditions on the bottom of formation
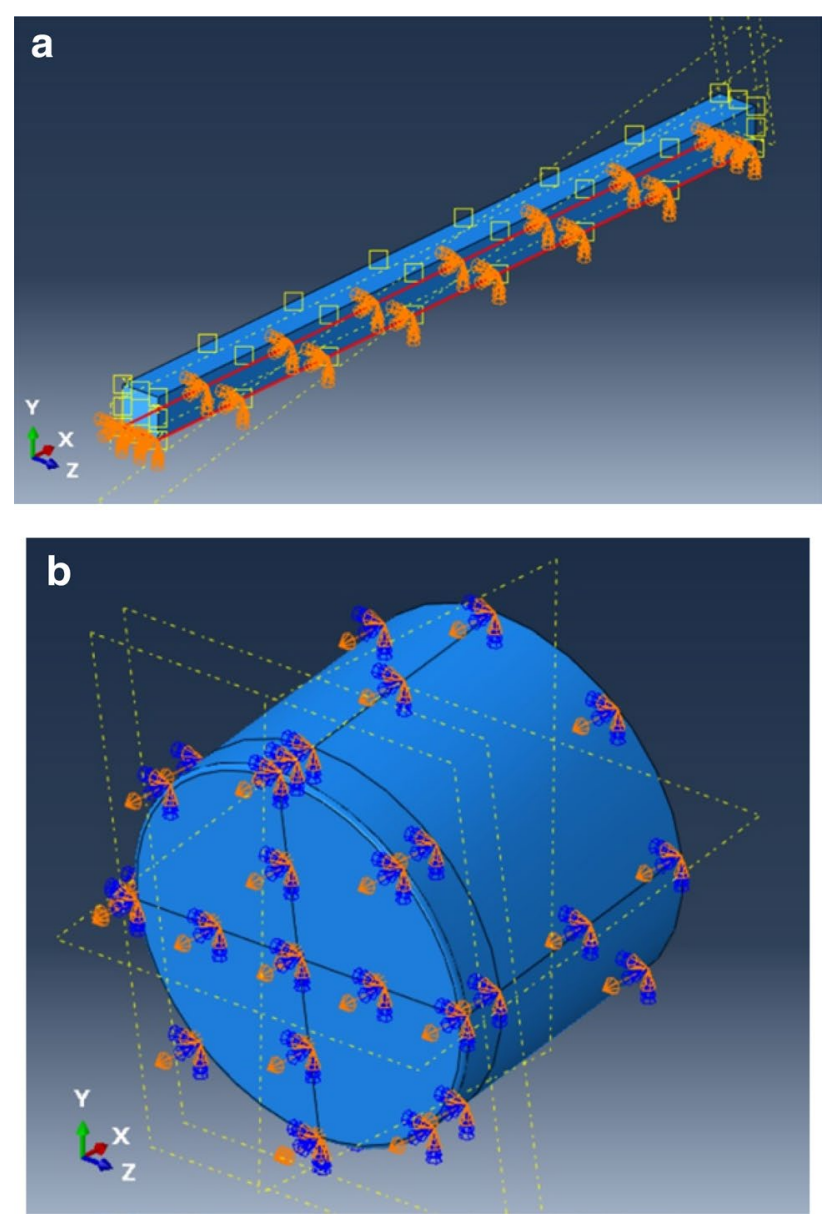

Fig. 5 a Cutter boundary condition, initial step. b Cutter boundary condition, cutting step displacement to all directions for the cutter was restricted. This boundary condition was later modified in the cutting step with the user-defined amplitude (Fig. 5a, b). Predefined fields are referred to initial condition data of the components. Within this study, initial temperature of the formation and cutter $\left(156^{\circ} \mathrm{C}\right.$ and $126^{\circ} \mathrm{C}$, respectively) was introduced as predefined fields.

\section{Mesh}

Mesh of the parts was adjusted to ensure the minimum number of elements while retaining the resolution of the results. Formation was meshed using a hex type structured mesh by defining the number of elements at the edges of the formation. Selected number of elements was 120 at $X$ direction, 20 at $Y$ direction, and 3 in $Z$ direction (Fig. 6). The concentration of the number of elements along either of axis was selected based on the anticipated amount of deformation at a given axis. For the cutters, the hex type mesh with sweep method was selected with the approximate global size of $1 \mathrm{~mm}$ (Fig. 7a-c).

\section{Job}

To submit the analysis, the memory allocation need to be defined. For this, the job menu is used. Within this menu, 9 job analyses were submitted to analyze the cases with 3 geometries and 3 fluid types. The summarized flowchart of modeling approach is illustrated in Fig. 8.

\section{Results and discussion}

The model thermal behavior validation was done in accordance with Kutasov and Eppelbaum (2015). Considerable agreement illustrated that the model can be used further to study thermal-mechanical wear of the drill bit cutters (Fig. 9).

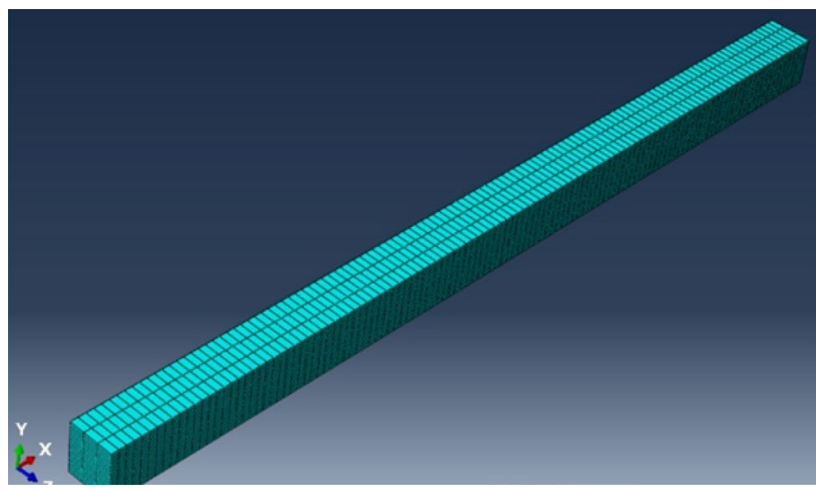

Fig. 6 Meshing of the formation 

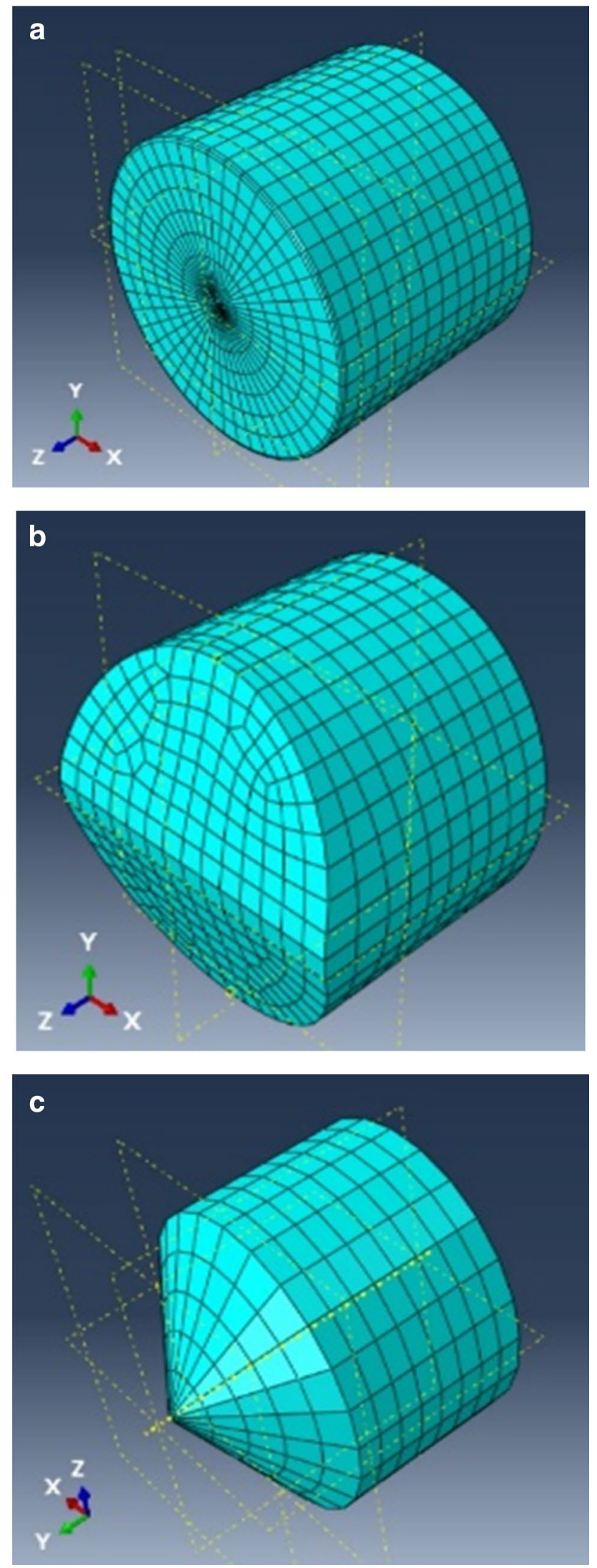

Fig. 7 a Chamfered cutter mesh. b Ax cutter mesh. c Stinger cutter mesh

$\checkmark$.

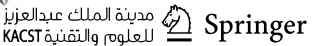

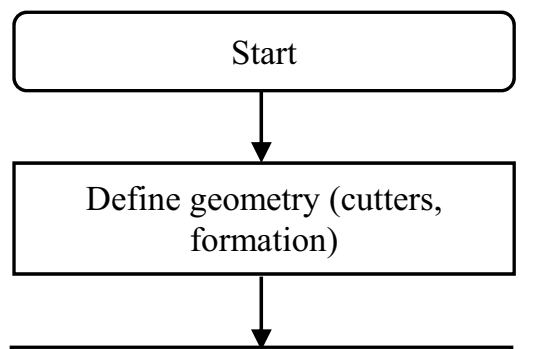

Define properties (PDC, tungsten carbide, formation)

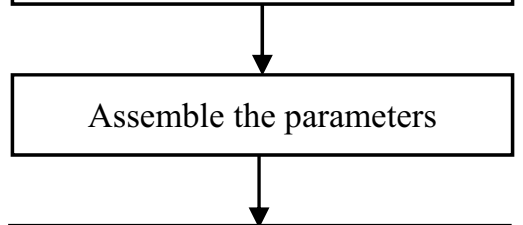

Define initial conditions (outer, boundary conditions and predefined fields)

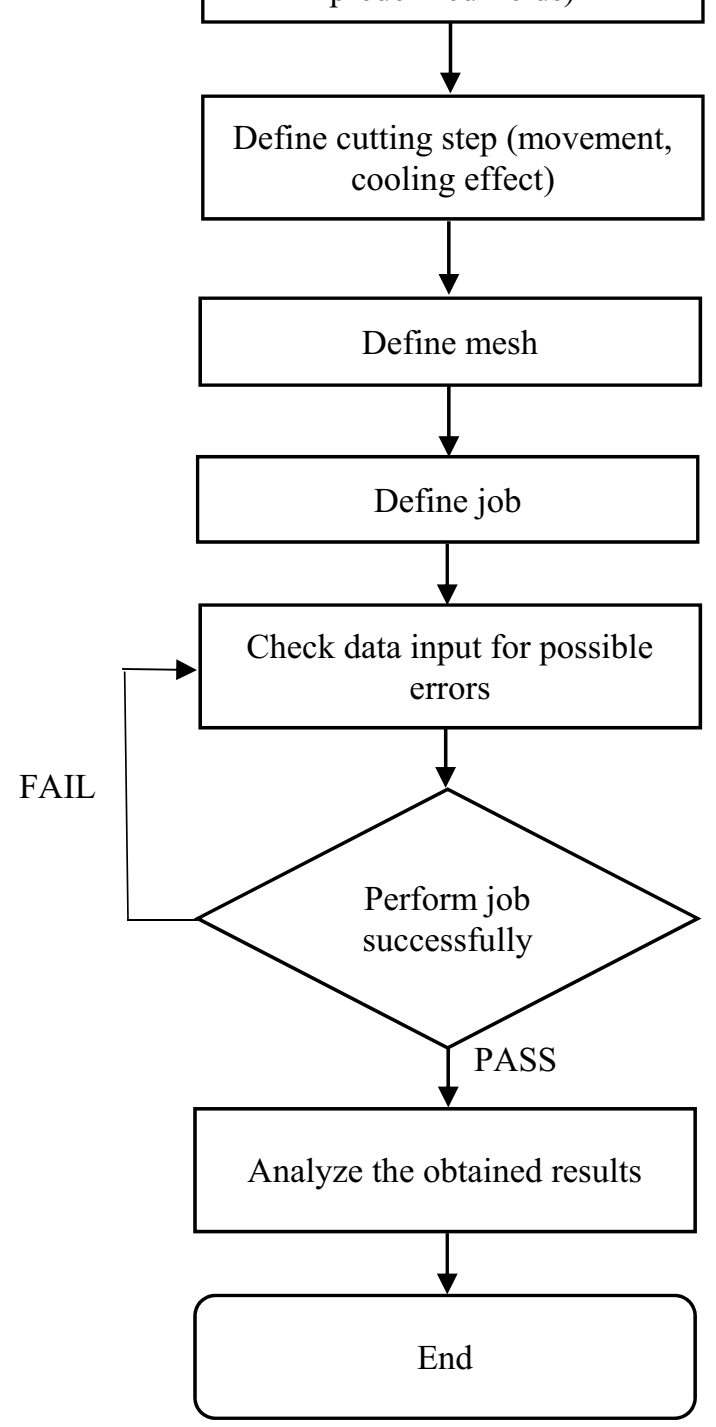

Fig. 8 Flowchart of the simulation 


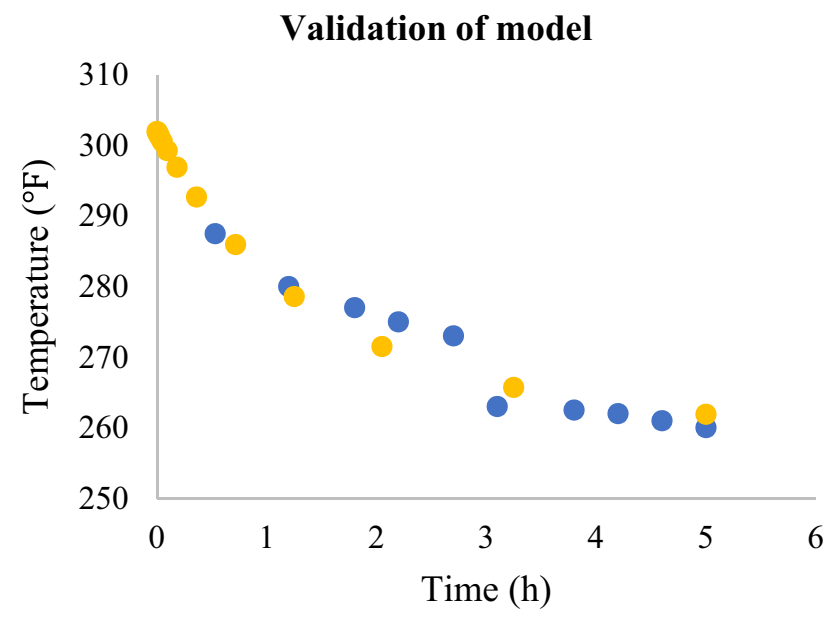

- Data provided in paper Simulation results

Fig. 9 Thermal behavior validation of the model

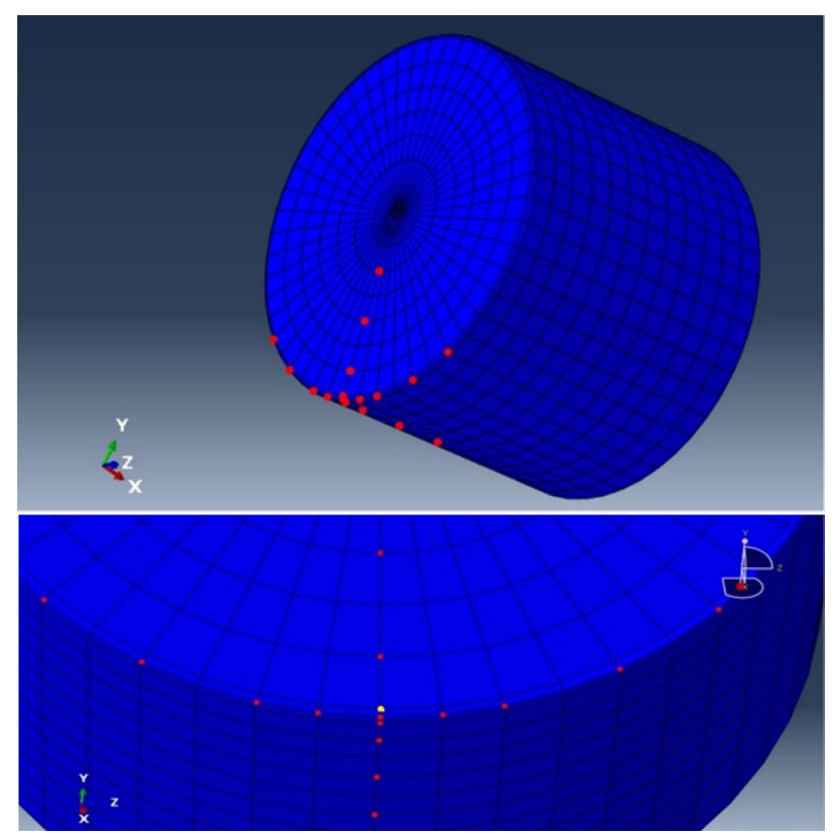

Fig. 10 Chamfered cutter nodes used for the analysis (yellow dot indicates the node with the highest temperature and force)

After validating the model, simulation was progressed to analyze the performance of each cutter and drilling fluid. The step time has been limited to $0.005 \mathrm{~s}$ due to the computer limitations. CPU time to simulate the cases varied from 3600 to 45,000 s using a PC with CORE i7-5500U $(2.40 \mathrm{GHz})$ and RAM memory of $8 \mathrm{~GB}$. The number of increments is ranged from 231,489 to $5,187,158$. As an output data, reaction forces and nodal temperature were referred. The nodes were selected as node of first contact being center and rest

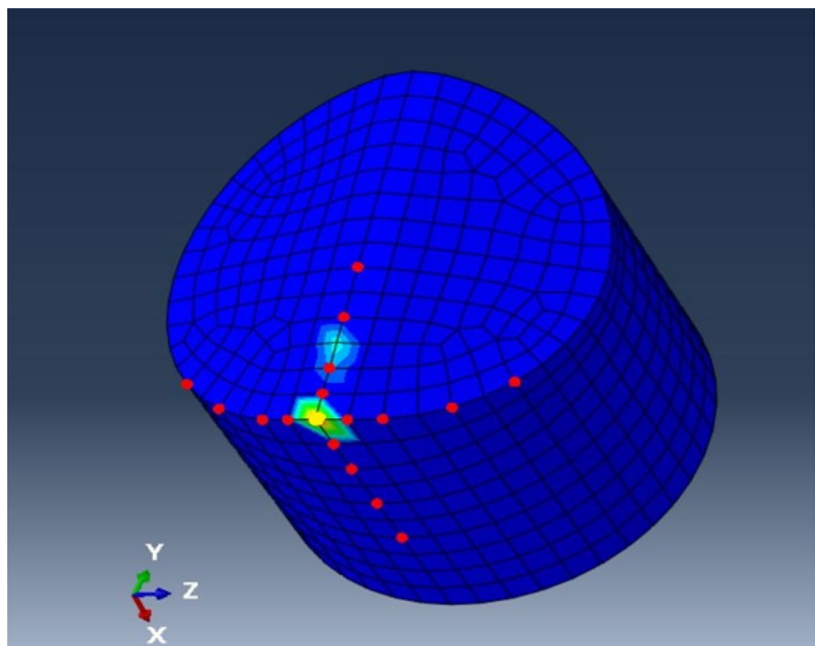

Fig. 11 Ax cutter nodes used for the analysis (yellow point indicates point of the highest force and temperature
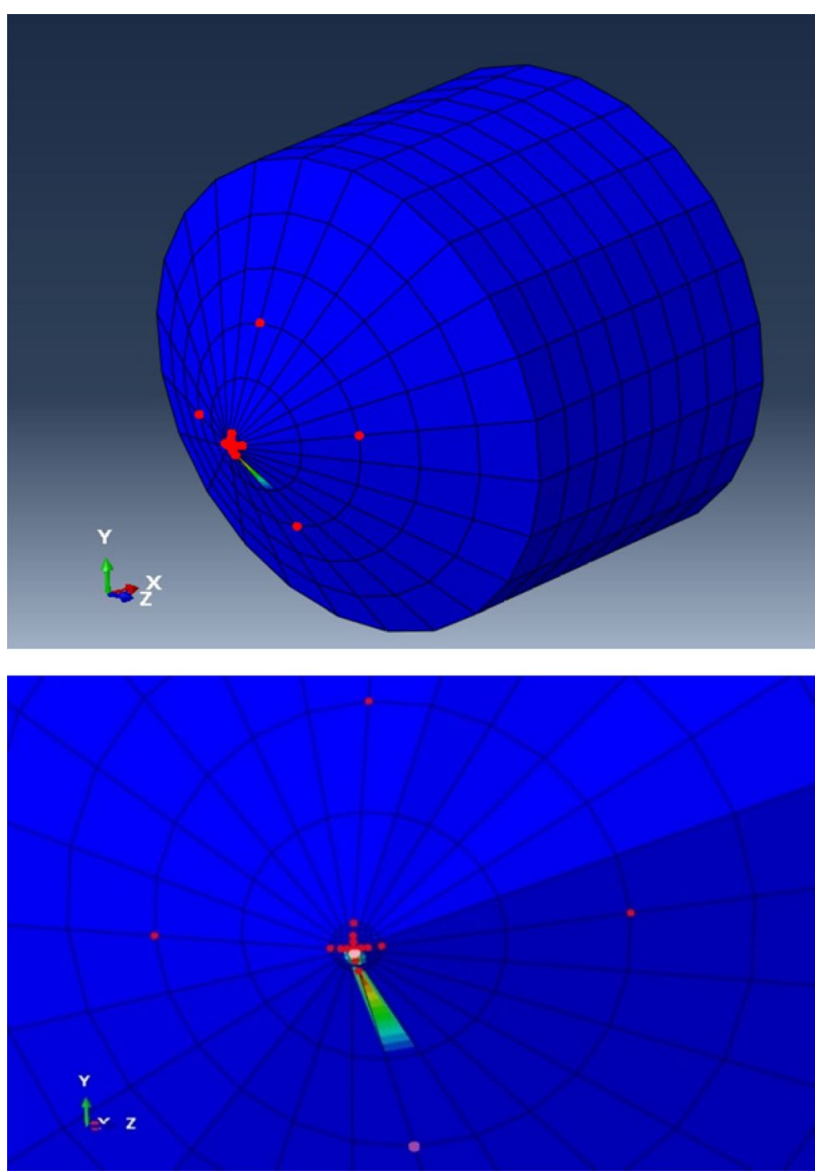

Fig. 12 Stinger cutter nodes used for the analysis (pink dot indicates the location with the highest temperature and violet dot is node with the highest force) 


\section{Cummulative wear vs time (OBM)}

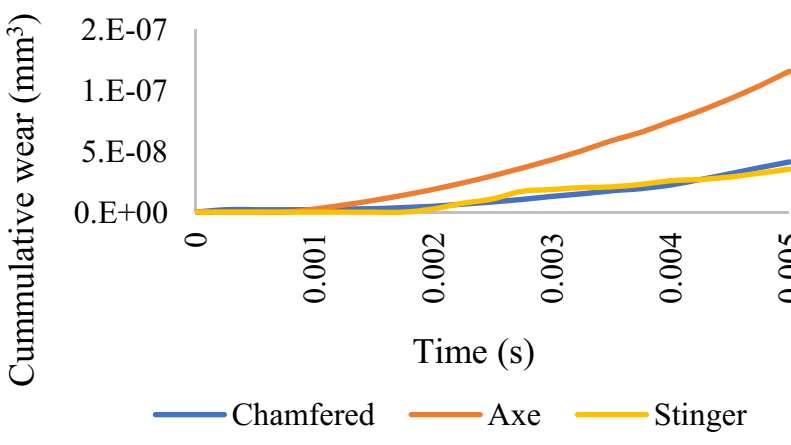

Fig. 13 Cumulative wear versus time with oil-based mud

\section{Cummulative wear vs time (WBM)}

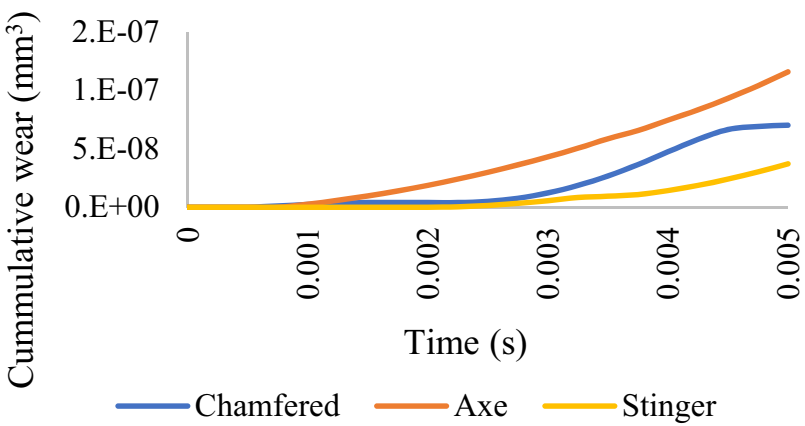

Fig. 14 Cumulative wear versus time with water-based mud

\section{Cummulative wear vs time (SBM)}

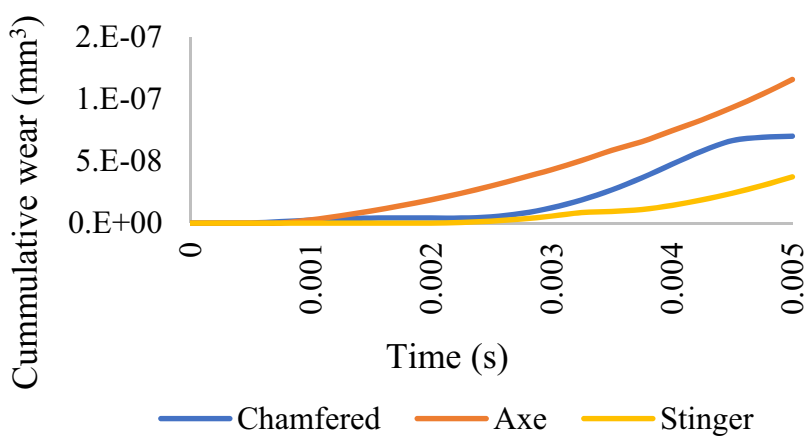

Fig. 15 Cumulative wear versus time with synthetic-based mud

of nodes extending in four perpendicular directions as demonstrated in Figs. 10, 11, and 12.

The force readings were converted to wear value and plotted as cumulative wear versus time to compare the performance of each drill bit cutter. The wear volume was computed based on Archard's wear estimation, where the wear rate is used. The wear rate of $1 \mathrm{E}-8 \mathrm{~mm}^{3} / \mathrm{Nm}$ was used (Yahiaoui et al. 2013). From Figs. 13, 14, and 15, it was

\section{Maximum temperature vs time (OBM)}

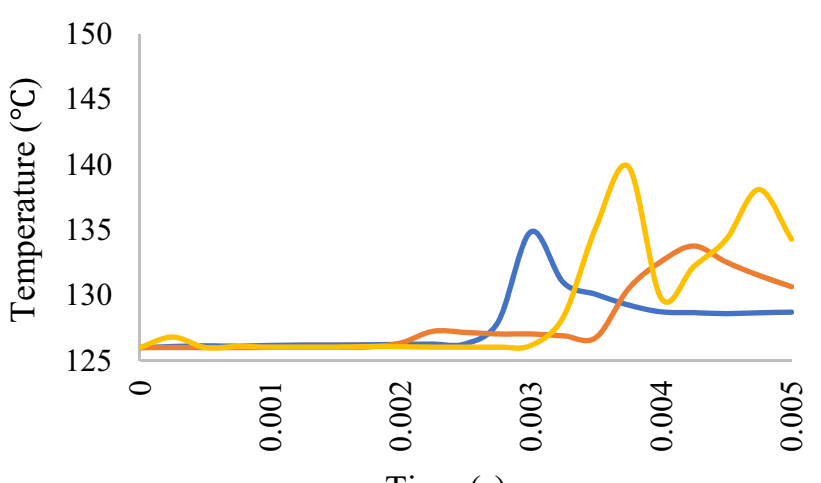

Time (s)

Chamfered $\longrightarrow$ Axe Stinger

Fig. 16 Maximum temperature versus time with oil-based mud

observed that drilling fluid type has effect only on chamfered type cutter mechanical wear performance which was also only in the case of oil-based mud.

The dependency of mechanical wear to the geometry of the cutter is a result of the surface area of contact between formation and cutter. The smaller contact area implies lower forces to break the formation at a location. If referred to molecular level, the forces required to separate molecules are directly related to the number of molecules and Van der Waals forces. As the force component remains same within the same material, the resultant force required will be a number of molecules separated at a time multiplied by the Van der Waals forces. The same analogy was present in the relation of cutter geometry and mechanical wear. Volumetric equivalent of the cutting fragments was highest for the ax type geometry due to the highest contact area and lowest for the stinger type geometry. Therefore, the least mechanical wear using SBM and WBM was seen in stinger type geometry while in OBM, the least mechanical wear was seen in chamfered type geometry.

In the analysis of the thermal wear, temperature readings for individual nodes were used as a qualitative measure to compare thermal wear for each cutter. This analogy was assumed to be valid due the materials being same for all cutters. From Figs. 16, 17, and 18, it was observed that the major affecting parameter for thermal wear was the drilling fluid type. Significance of the fluid type rises as the contact area of the coolant and cutter reduces. As the contact area of the drilling fluid for the stinger type cutter was the smallest, it was affected the most and showed the least thermal wear when used with synthetic-based mud (SBM). For chamfered type geometry, the least thermal wear was observed using oil-based mud (OBM), while the cooling effect for water-based mud (WBM) and SBM showed the same trend. There was no significant difference 


\section{Maximum temperature vs time (WBM)}

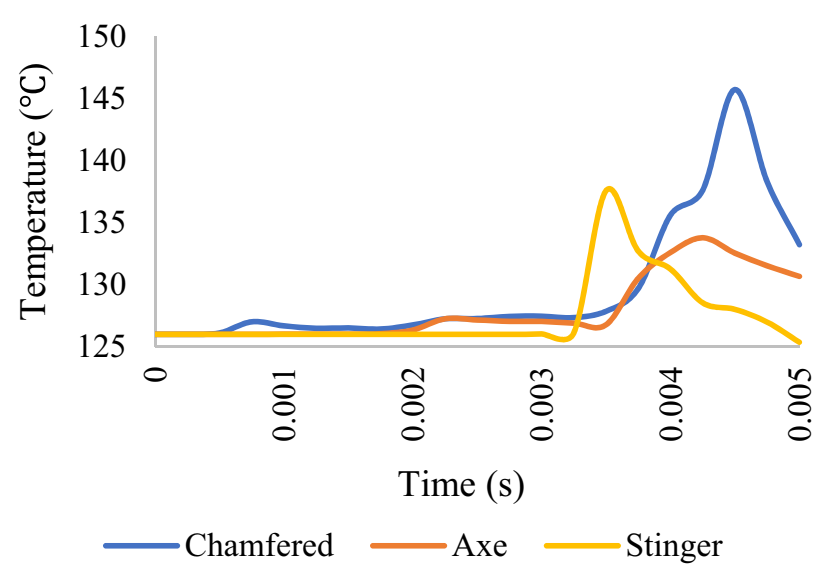

Fig. 17 Maximum temperature versus time with synthetic-based mud

\section{Maximum temperature vs time (SBM)}

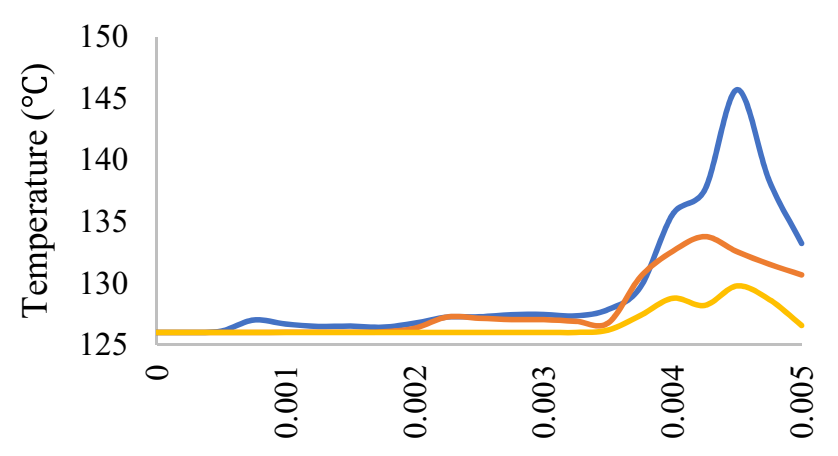

Time (s)

Chamfered $\longrightarrow$ Axe $\longrightarrow$ Stinger

Fig. 18 Maximum temperature versus time with water-based mud

in thermal wear that was observed for ax geometry due to the geometry providing sufficient contact to reduce the heat to a possible minimum.

Based on the above results, the best combination to be used was standard chamfered cutter geometry with OBM or stinger cutter geometry with SBM. However, to further validate the above results, experimental tests are required.

\section{Conclusions}

In this study, thermal-mechanical wear of three specific PDC cutters: standard chamfered, ax, and stinger was investigated, on the application of heat flux and cooling effect by different drilling fluids by using FEM. The following results can be concluded:
- Mechanical wear rate of the cutter is dependent on the interaction between the surface of the cutter and formation. Volumetric equivalent of the cutting fragments was highest for the ax and lowest for the stinger because of their specified design. Therefore, the highest mechanical wear was identified in ax.

- Drilling fluids were one of the main properties that effected on thermal wear of PDC cutters. Stinger type cutter showed least thermal wear because of its design features when used with synthetic-based mud (SBM). For chamfered type geometry, the least thermal wear was observed using oil-based mud (OBM).

Verification and validation is a critical factor in the development of the simulation model. Therefore, it is suggested to perform experimental work to validate the observed output data from simulation studies.

Acknowledgements The authors would like to thank Petroleum Engineering Department and Institute of Hydrocarbon Recovery at Universiti Teknologi PETRONAS for the funding (STIRF-0153AA-F78).

Open Access This article is distributed under the terms of the Creative Commons Attribution 4.0 International License (http://creativeco mmons.org/licenses/by/4.0/), which permits unrestricted use, distribution, and reproduction in any medium, provided you give appropriate credit to the original author(s) and the source, provide a link to the Creative Commons license, and indicate if changes were made.

\section{References}

Al-Muhailan M, Hussain I, Maliekkal H, Ghoneim O, Nair P, Fayed M (2013) New HTHP cutter technology coupled with FEA-based bit selection system improves ROP by $60 \%$ in abrasive Zubair formation. In: IPTC 2013: international petroleum technology conference

Azar M, White A, Segal S, Velvaluri S, Garcia G, Taylor M (2013) Pointing towards improved PDC bit performance: innovative conical shaped polycrystalline diamond element achieves higher ROP and total footage. In: SPE/IADC drilling conference. Society of Petroleum Engineers

Bilgesu I, Sunal O, Tulu IB, Heasley KA (2008) Modeling rock and drill cutter behavior. American Rock Mechanics Association, San Francisco

Curry DA, Lourenco AM, Ledgerwood III LW, Maharidge RL, da Fontoura S, Inoue N (2015) SPE/IADC-173023-MS

Freeman MA, Shen Y, Zhang Y (2012) Single PDC cutter studies of fluid heat transfer and cutter thermal mortality in drilling fluid. In: AADE national technical conference and exhibition, Houston, TX, paper no. AADE-12-FTCE-38

Ju P, Wang Z, Zhai Y, Su D, Zhang Y, Cao Z (2014) Numerical simulation study on the optimization design of the crown shape of PDC drill bit. J Pet Explor Prod Technol 4(4):343-350

Kutasov IM, Eppelbaum LV (2015) Wellbore and formation temperatures during drilling, cementing of casing and shut-in. In: Proceedings of the world geothermal congress, pp 19-25

Oliveira GD, Freesz MP, Izbinski KT, Valbuena F, Carvalho DJ, Alonso A (2015) Unique hybrid drill bit with novel PDC cutters

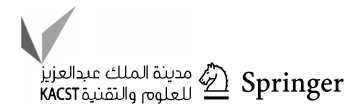


improves performance in ultra-deepwater Brazil pre-salt application. In: OTC Brasil. Offshore technology conference

Pei J, Yinghu Z, Zhenquan W, Dongyu S (2013) Numerical simulation of polycrystalline diamond compact bit rock-breaking process based on smooth particle hydrodynamic-finite element coupling method. Научные труды НИПИ Нефтегаз ГНКАР 3(3):32-38

Rani AMA, Khartigesan A, Ganesan L (2015) Reverse engineering of PDC drill bit design to study improvement on rate of penetration. In: Mathematical methods and systems in science and engineering. ISBN: 978-1-61804-281-1

Stockey D, DiGiovanni A, Fuselier D, Gavia D, Zolnowsky M, Phillips R, Ridgway D (2014) Innovative non-planar face PDC cutters demonstrate $21 \%$ drilling efficiency improvement in interbedded shales and sand. Society of Petroleum Engineers, Dallas. https:// doi.org/10.2118/168000-ms

Yahiaoui M, Gerbaud L, Paris JY, Denape J, Dourfaye A (2013) A study on PDC drill bits quality. Wear 298:32-41

Yari N, Kapitaniak M, Vaziri V, Ma L, Wiercigroch M (2018) Calibrated FEM modelling of rock cutting with PDC cutter. In: MATEC web of conferences

Publisher's Note Springer Nature remains neutral with regard to jurisdictional claims in published maps and institutional affiliations. 